\title{
Managing Complications and Revisions in Sinus Surgery
}

\author{
A. Khanna ${ }^{1} \cdot$ A. Sama ${ }^{2}$
}

Published online: 3 April 2019

(C) The Author(s) 2019

\begin{abstract}
Purpose of Review To discuss strategies to avoid, identify and deal with both minor and major complications, as well as indications for revision sinus surgery.

Recent Findings Complication rates from endoscopic sinus surgery are low and have improved with increased surgical experience and new technology. Early extensive surgery in patients with complex sinonasal disease can improve long-term outcomes. Summary A majority of patients undergoing endoscopic sinus surgery have a positive outcome. The surgeon must be competent in recognising and dealing with potential complications, as well as approaching complex revision cases.
\end{abstract}

Keywords Frontal sinus surgery $\cdot$ Complications in sinus surgery $\cdot$ Revision sinus surgery $\cdot$ Chronic rhinosinusitis

\section{Introduction}

Functional endoscopic sinus surgery (FESS) is one of the commonest procedures performed by a rhinologist. Over 250,000 FESS cases are performed annually in the USA alone, the majority for chronic rhinosinusitis with or without nasal polyposis [1]. Complication rates have reduced as training, experience and comfort with endoscopes and powered instruments have increased. In experienced hands, minor complication rates of 5\% and major complication rates below $1 \%$ are cited [2-4]. While the majority of patients undergoing FESS will require a single operation, $10-19 \%$ of patients will require revision surgery [5-7].

We discuss strategies to avoid, identify and deal with both minor and major complications, as well as indications for revision sinus surgery.

This article is part of the Topical Collection on RHINOLOGY: Chronic Rhinosinusitis

\section{A. Sama}

anshul.sama@nottingham.ac.uk

1 Charing Cross Hospital, London, UK

2 Nottingham University Hospital, Nottingham, UK

\section{Anatomy}

The FESS surgeon must have an intricate understanding of sinonasal anatomy, including potential physiological and pathological variations. This knowledge can then be applied to the individual patient's pathology. High-resolution computed tomography $(\mathrm{CT})$ of the paranasal sinuses with triplanar reconstructions is accepted as the minimum standard for visualisation of sinonasal disease. The CLOSE mnemonic is a well-known adjunct (Table 1, reprinted with permission from [8]) for assessing CT scans for potential surgical pitfalls [8]. Nevertheless, the surgeon must be prepared to encounter unexpected pathology during surgery, especially if there has been a delay between the CT scan and FESS [9].

\section{Experience}

As with all surgical skills, there is a "learning curve" associated with FESS. The FESS surgeon should be competent with undertaking emergency procedures to stabilise patients and rectify acute complications such as intra-orbital haematoma. Trainees should participate in cadaveric dissection courses and then perform diagnostic endoscopic procedures, allowing them to become comfortable with the endoscope, camera, orientation within the nasal cavity and three-dimensional interpretation of two-dimensional live images. 
The first 100 procedures performed by solo inexperienced surgeons generally have a higher complication rate [2]. Studies have shown that, when performed in a training environment under guidance of an experienced FESS surgeon, there is no increase in complication rate during the learning curve period $[2,3]$.

\section{Bleeding}

A thorough pre-operative history will alert the surgeon of potential increased bleeding risks. Anti-coagulants should be stopped with an appropriate time interval to allow clotting to normalise. Haematological advice should be sought when bridging heparinisation may be required. Patients with known bleeding disorders should be managed according to protocols agreed with the haematology team. Beware of patients using over-the-counter vitamins and herbal therapies as these can impact on the clotting time.

\section{Mucosal Bleeding}

Careful insertion of the Hopkins rigid endoscope and instruments will minimise mucosal trauma. Localised superficial bleeding can be controlled with topical epinephrine-soaked patties, reserving bipolar cautery for refractory bleeds. Hypotensive total intravenous anaesthesia (TIVA) provides a clearer surgical field with less bleeding compared with gaseous anaesthetic agents [10].

The post-operative removal of nasal packing is very distressing for the patient and causes unnecessary trauma to the mucosal lining. Dissolving nasal packs show some evidence of reducing post-operative adhesions [11]; despite a general subjective feeling that they reduce post-operative bleeding, this is not backed up by a recent systematic review [12].

\section{Sphenopalatine Artery}

The sphenopalatine artery, or a branch of, may be traumatised at its point of exit from the sphenopalatine foramen during posterior enlargement of the middle meatal antrostomy, or at its septal branch during inferior enlargement of the sphenoidotomy (Fig. 1). The surgeon should be comfortable performing endoscopic ligation or bipolar cauterisation of this vessel if required. A submucosal elevation of the mucosa on face of sphenoid before enlarging the bony antrostomy can prevent damage to the septal branch.

\section{Anterior Ethmoidal Artery}

Orbital haematoma from anterior ethmoidal artery (AEA) damage during FESS is rare, with an incidence of $0.3 \%$ [13]. The AEA may be within the canalis orbitocranialis in the skull base, caudal to the skull base in $60 \%$ of cases or dehiscent in up to $40 \%$ [14-16] (Fig. 2). An avulsed AEA may retract into the orbital cavity, presenting with severe rapid proptosis and a firm eye. It is therefore advisable to always use cutting instruments in the ethmoid roof. Immediate management with endoscopic medial orbital decompression or lateral canthotomy or a combination is required to prevent optic nerve ischaemia and loss of vision [17].

Delayed-onset post-operative AEA bleeding typically presents in the recovery suite, possibly with lid bruising and ecchymosis before development of proptosis (Fig. 3). With less than 60 min before irreversible retinal ganglion neurodegeneration [18], urgent decompression by way of lateral canthotomy in the recovery suite may be required. The patient may then be returned to the operating room for formal endoscopic medial decompression if required.

\section{Internal Carotid Artery}

Damage to the internal carotid artery (ICA) with standard FESS is vanishingly rare, with an incidence historically quoted as $0.3 \%$ but commonly accepted as much lower with improved surgeon experience, CT scan quality and higher resolution endoscopy [2]. The cavernous segment
Table 1 CLOSE mnemonic to assess for anatomical abnormalities during FESS

\begin{tabular}{lll}
\hline Structure & Scan & Concern \\
\hline Cribriform plate & Coronal & $\begin{array}{l}\text { (i) Keros classification } \\
\text { (ii) Asymmetry }\end{array}$ \\
$\begin{array}{ll}\text { Lamina papyracea } \\
\text { Onodi cells/optic nerve }\end{array}$ & $\begin{array}{l}\text { Coronal } \\
\text { (i) Dehiscences or orbital prolapse from previous surgeries } \\
\text { (i) Identification of Onodi cells }\end{array}$ \\
Sphenoid/skull base & $\begin{array}{l}\text { Coronal } \\
\text { Sagittal }\end{array}$ & $\begin{array}{l}\text { (i) The Thiscent optic nerve/carotid within sphenoid/Onodi } \\
\text { (ii) Note lateral sphenoid landmarks }\end{array}$ \\
Ethmoid artery & $\begin{array}{l}\text { Coronal } \\
\text { Sagittal }\end{array}$ & (i) Identification of anterior ethmoid arteries hanging on a mesentery \\
\hline
\end{tabular}

Reprinted with permission from [8] 


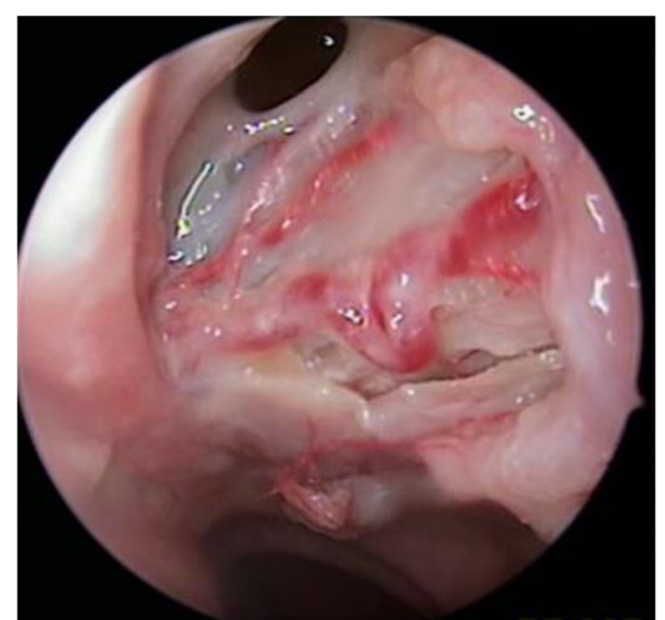

Fig. 1 Anatomical dissection of the face of the right sphenoid demonstrating course of the septal branch of the sphenopalatine artery

of the ICA is at risk during sphenoidotomy due to its relationship with the lateral wall of the sphenoid sinus. The ICA may protrude significantly into the sphenoid sinus in $15 \%$ of cases; the overlying bone may be thin in $20 \%$, and dehiscent in $15 \%$ of cases; $1 \%$ of patients may have an intersinus septation connecting with the ICA [2]. Sphenoethmoidal (Onodi) cells may be present in up to $40 \%$ of patients [19]; the ICA may be dehiscent within this cell and therefore at risk of damage (Fig. 4).

Endoscopic skull base surgery (ESBS) necessitates greater exposure of the ventral and anterior skull base, increasing the risk of ICA injury; thankfully, in experienced hands, the incidence of ICA injury in ESBS is below 1\% [20]. Pre-operative contrast CT and MRI angiography allow appreciation of variations in ICA pathways and distortion due to surrounding or invading mass lesions [21]. The ICA can be damaged at any point along its path, although the left cavernous segment is still most at risk [22].

Should an ICA injury occur, the surgeon should gain immediate local control with direct pressure, utilise suction and irrigation to clear the surgical field, gain proximal and distal control (extending the dissection if required) and then assess

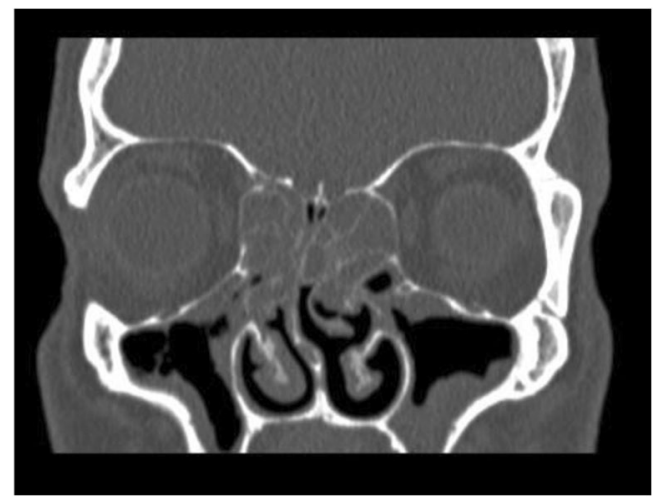

Fig. 2 Coronal CT scan showing anterior ethmoid artery canal within the skull base (left) and below the skull base (right) the ICA injury to determine salvage options. Sheep model experiments have shown crushed muscle patch or use of an aneurysm clip to be effective measures for controlling acute ICA injury [23]. It should be borne in mind that over $80 \%$ of patients will tolerate ICA sacrifice [24]. Inability to control bleeding should be managed by balloon occlusion and immediate angiography.

Following acute management of an ICA injury, postoperative angiography is mandatory. Residual active bleeding or formation of a pseudoaneurysm is an indication for endovascular management by interventional radiology or vascular teams.

\section{Orbital Damage}

Damage to intraocular contents is thankfully incredibly rare. A large single-centre review [17] found the right eye to be at greater risk than the left, possibly due to the majority of surgeons being right-handed. The medial rectus muscle was found to be the most commonly injured, leading to strabismus and diplopia; should this persist, medial orbital wall reconstruction and strabismus surgery may provide benefit. If orbital contents are exposed, it is advised not to instrument the orbital contents, though gentle bipolar to the prolapsing orbital fat can allow continued access to complete the procedure. Failure to differentiate orbital fat from intranasal contents, with continued microdebrider use, can lead to irreversible damage and complete loss of vision [25].

The optic nerve may be dehiscent in the sphenoid sinus in $4 \%$ of cases, and sphenoethmoidal air cells may contain a dehiscent optic nerve as well as the ICA [19] (Fig. 4). The risk to the optic nerve can be reduced by careful study of preoperative triplanar CT scans, looking for these anatomical variations.

In case of inadvertent exposure of orbital contents, the patient should be advised to avoid blowing their nose for 2 weeks to reduce the chance of orbital emphysema. Any damage to orbital contents should be managed in conjunction with the ophthalmology team.

\section{Damage to Nasolacrimal Duct}

The nasolacrimal duct may be dehiscent in up to $7 \%$ of patients [26]. Aggressive removal of the uncinate bone with a back-biting instrument and anterior overenlargement of the middle meatal antrostomy may lead to excess bone removal in $3 \%$ of cases [26], and may damage the duct itself, leading to epiphora. In recalcitrant cases failing non-surgical ophthalmological intervention, dacrocystorhinostomy may be required. 


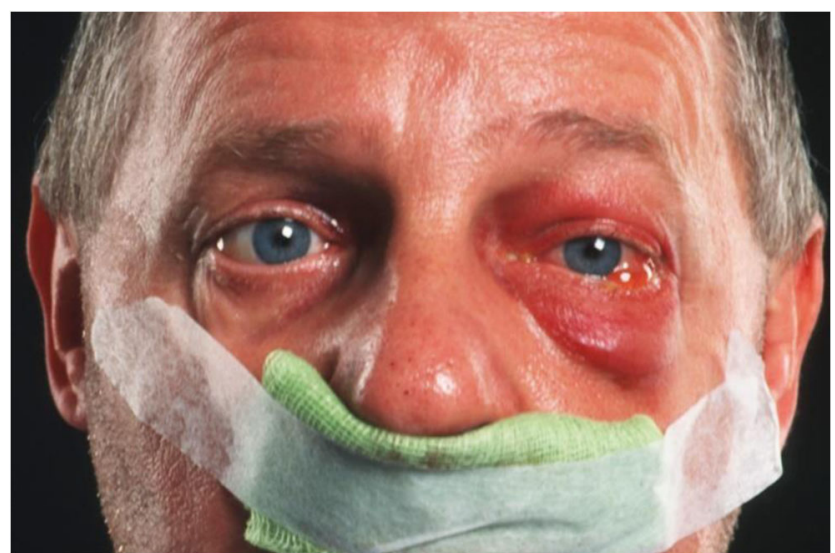

Fig. 3 Clinical image of the patient with evidence of post-operative orbital haemorrhage in recovery. With any orbital damage, the ophthalmology team must be involved urgently, both to assess vision and to manage sequelae

\section{Cerebrospinal Fluid Rhinorrhoea}

Cerebrospinal fluid (CSF) rhinorrhoea can be due to defects anywhere along the anterior and lateral skull base. Lateral skull base CSF leak can present with CSF rhinorrhoea by passage via the Eustachian tube. Anterior skull base CSF leaks may be idiopathic, traumatic or iatrogenic; CSF leaks associated with standard FESS are rare, with an incidence of $0.2 \%$ [27], but may be due to both anatomical and technical factors [28]. The extended skull base exposure with ESBS increases the incidence of CSF leak to 7\% [29]. Common sites for

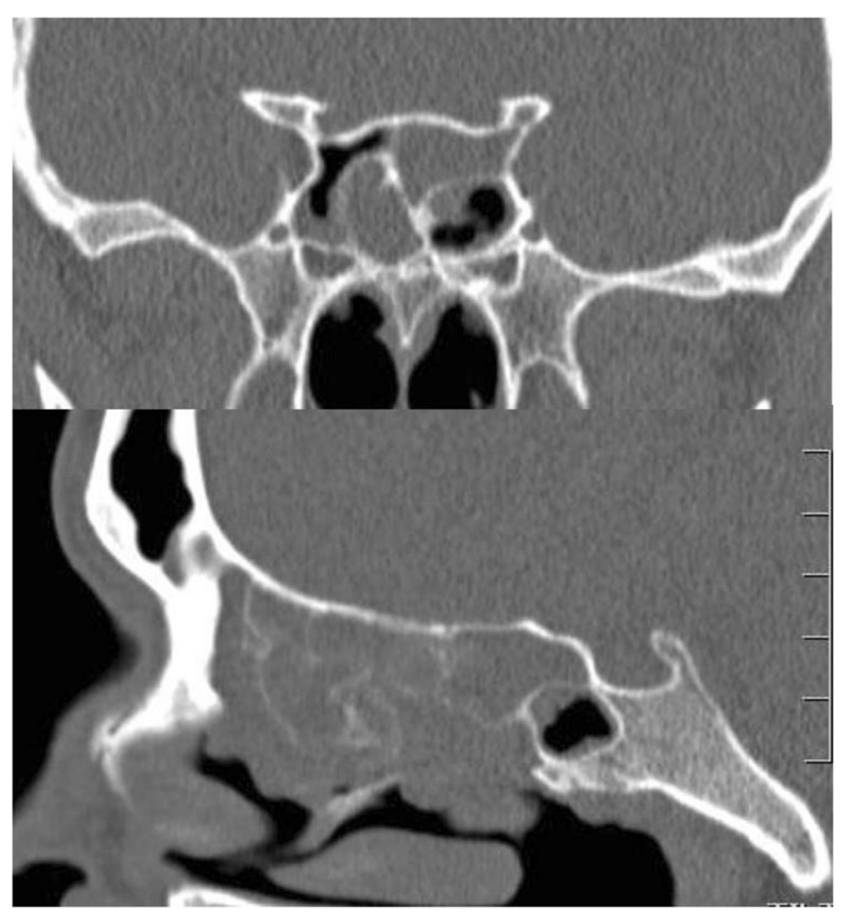

Fig. 4 Coronal and sagittal CT scan images demonstrating a posterior sphenoethmoid cell anterior skull base defects are in the ethmoid and sphenoid sinuses [30, 31]. Recognising skull base damage and subsequent CSF leak during initial FESS allows concurrent repair; missed skull base damage may require additional surgical reparative procedures, adding to the patient's morbidity and inpatient stay [32].

Accurate diagnosis of the source and aetiology of a CSF leak is imperative in aiding surgical planning for repair. Highresolution CT is useful to locate bony defects in the skull base, and to rule out an otological cause. MRI and MR cisternography are useful in situations of multiple bony defects, or where the site of defect cannot be identified on CT [33]; CT cisternography may be reserved for cases where these have failed to identify a source. Intrathecal perioperative fluorescein can be utilised in cases where all available imaging modalities have been exhausted [30].

Multiple repair methods have been described. Accepted methods involve a three-layer approach to repair dura, substitute the bony defect and then to provide mucosal cover [34-36]. While a clean operative field is preferred, CSF leak repair may be carried out in patients with acute sinus infections or meningitis without added risk of complications [37].

\section{Intracranial Complications}

\section{Infection}

Post-FESS intracranial infections may present as meningitis, intracranial abscess or cavernous sinus thrombosis. The risk of meningitis with a persistent CSF leak is $19 \%$, decreasing after repair of the skull base defect [38]. Abscesses will require urgent neurosurgical drainage and therefore should be managed in the appropriate tertiary unit. All intracranial infections should be managed in a multidisciplinary environment, involving physicians, neurology and microbiology.

\section{Pneumocephalus}

Pneumocephalus is an uncommon complication of FESS. Tension pneumocephalus post-FESS is incredibly rare; only a handful of isolated cases have been described in the literature [39-42]. All cases of pneumocephalus must be managed in conjunction with neurosurgical teams in a tertiary unit. While very small, uncomplicated cases may be managed with bed rest and administration of $100 \%$ oxygen; the majority will require surgical repair of the underlying bony defect [43]. Tension pneumocephalus will require urgent surgical decompression along with repair of the defect to prevent brain herniation [40]. 


\section{Revision FESS}

As with all surgical interventions, the aim of FESS should be to provide appropriate resolution of pathology without recurrence of disease. Despite this admirable aim, the reality is that up to $20 \%$ of patients will require revision FESS within 5 years, $43 \%$ of which will be within the first post-operative year [5]. A lack of anatomical and physiological understanding can increase the need for revision surgery [44]. Risk factors for requirement of revision surgery are listed in Table 2 [6, 45-47]. Both the surgeon and patient should be aware that revision FESS carries an increased overall risk of complications and need for further revision surgery [48-50].

\section{More Extensive Surgery}

In patients with conditions known to have high recurrence rates, there is an argument for early, extensive surgical intervention [51]. Aspirin-exacerbated respiratory disease is frequently associated with nasal polyps, a trio of disease known as Samter's triad (Fig. 5). These patients typically have more severe nasal polyposis as compared with aspirin-tolerant patients [52]. Recurrence rates post-FESS of up to $90 \%$ have been reported in this group [6]. Indeed, the authors have managed patients previously treated at other units who have presented for their 18th FESS procedure. A low threshold for maxillary antrostomy, complete sphenoethmoidectomy and modified Lothrop procedure can reduce recurrence to $22.5 \%$ [53].

The inverted papilloma, a subtype of Schneiderian papillo$\mathrm{ma}$, is a benign but locally aggressive tumour with malignant potential [54], commonly affecting the nose and paranasal sinuses. Increasing Krouse staging score [55] will necessarily require more extensive resection. Identification of the location of attachment and adequate resection reduce risk of recurrence [56]. The importance of sending abnormal-looking tissue and nasal polyps for histopathological analysis cannot be overemphasised. Missed inverted papilloma can continue to progress in situ, presenting with complications including frontal pyoceles [57]. Resection of frontal sinus inverted papilloma is associated with up to $37 \%$ incidence of mucocele

Table 2 Risk factors for requiring revision FESS

\begin{tabular}{l}
\hline Nasal polyposis \\
Inverted papilloma \\
Allergic fungal rhinosinusitis \\
Frontal sinus disease \\
Cystic fibrosis \\
Obesity \\
Immune deficiency \\
Smoking \\
Female gender
\end{tabular}

formation; this is higher in combined endoscopic and open techniques than endoscopic alone [58,59].

Obstruction of the frontal sinus outflow tract (FSOT) following FESS or EDCR can lead to the formation of frontal mucocele. This may be due to adhesions or lateralisation of the middle turbinate [60], both of which can obstruct the FSOT. This may expand into the orbit or become infected leading to a pyocele and associated intracranial complications.

The nasalisation technique, involving giant middle meatus antrostomy, middle turbinate resection, complete sphenoethmoidectomy and dissection of the FSOT cells, is associated with reduced incidence of recurrence but increased incidence of mucoceles; this can be reduced by preserving the horizontal portion of the basal lamella and the lateral insertion to the palatine bone [61].

\section{Adhesions}

Adhesions post-FESS can cause nasal obstruction and recurrence of CRS, requiring revision FESS. Instillation of topical hyaluronic acid with hydroxyethyl starch or carboxymethylcellulose has been shown to reduce the incidence of post-operative adhesions [62, 63]. Atraumatic endoscopy and instrumentation techniques minimise the incidence of adhesions.

\section{Technology}

The use of high-quality operating equipment assists the sinus surgeon with visualisation and instrumentation during FESS [64]. The ever-increasing variety of two- and three-dimensional endoscopes, microdebriders and drills allow the surgeon to find the instrument he or she is most comfortable with.

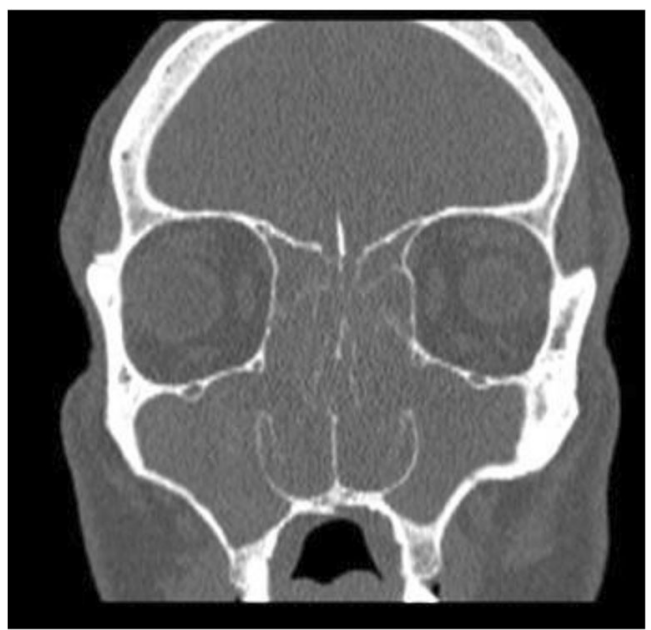

Fig. 5 Typical coronal CT scan of patient with aspirin-sensitive airway disease and nasal polyposis 
Image-guided navigation systems are useful adjuncts in revision FESS cases, where normal anatomical landmarks may be distorted or previously resected. The American Association of Otolaryngology-Head and Neck Surgery advocates the use of navigation systems for advanced FESS, revision cases and tumour resection [65]. A large meta-analysis has shown reduction in overall and major complication rates with the use of image-guided navigation during FESS [66].

\section{Conclusion}

A majority of patients undergoing FESS have a positive outcome from a single operation, with no morbidity or recurrence. The FESS surgeon must be competent in recognising and dealing with potential complications, as well as approaching complex revision cases.

\section{Compliance with Ethical Standards}

Conflict of Interest The authors declare that they have no competing interests.

Human and Animal Rights and Informed Consent This article does not contain any studies with human or animal subjects performed by any of the authors.

Open Access This article is distributed under the terms of the Creative Commons Attribution 4.0 International License (http:// creativecommons.org/licenses/by/4.0/), which permits unrestricted use, distribution, and reproduction in any medium, provided you give appropriate credit to the original author(s) and the source, provide a link to the Creative Commons license, and indicate if changes were made.

\section{References}

Papers of particular interest, published recently, have been highlighted as:

- Of importance

-• Of major importance

1. Pynnonen MA, Davis MM. Extent of sinus surgery, 2000-2009: a population-based study. Laryngoscope. 2014:820-5.

2. Hosemann W, Draf C. Danger points, complications and medicolegal aspects in endoscopic sinus surgery. GMS Curr Top Otorhinolaryngol Head Neck Surg. 2013;12:Doc06.

3. Hopkins C, Browne JP, Slack R, Lund VJ, Topham J, Reeves BC, et al. Complications of surgery for nasal polyposis and chronic rhinosinusitis: the results of a national audit in England and Wales. Laryngoscope. 2006;116:1494-9.

4.• Chou T-W, Chen P-S, Lin H-C, Lee K-S, Tsai H-T, Lee J-C, et al. Multiple analyses of factors related to complications in endoscopic sinus surgery. J. Chin. Med. Assoc. 2016;79:88-92. This study shows that there is no increase in complication rates with the use of the microdebrider.
5. Stein NR, Jafari A, DeConde AS. Revision rates and time to revision following endoscopic sinus surgery: a large database analysis. Laryngoscope. 2018;128:31-6. This study shows that patients with nasal polyps are more likely to require revision surgery than those without polyps.

6. Mendelsohn D, Jeremic G, Wright ED, Rotenberg BW. Revision rates after endoscopic sinus surgery: a recurrence analysis. Ann Otol Rhinol Laryngol. 2011;120:162-6.

7. Hopkins C, Slack R, Lund V, Brown P, Copley L, Browne J. Longterm outcomes from the English national comparative audit of surgery for nasal polyposis and chronic rhinosinusitis. Laryngoscope. 2009;119:2459-65.

8. Weitzel EK, Floreani S, Wormald P-J. Otolaryngologic heuristics: a rhinologic perspective. ANZ J. Surg. 2008;78:1096-9. https://doi. org/10.1111/j.1445-2197.2008.04757.x.

9.• Hopkins C, Rimmer J, Lund VJ. Does time to endoscopic sinus surgery impact outcomes in chronic rhinosinusitis? Prospective findings from the National Comparative Audit of Surgery for Nasal Polyposis and Chronic Rhinosinusitis. Rhinology. 2015;53: 10-7. This study shows that patients with asthma are more likely to experience a delay in surgical intervention compared with other patients. This study also shows that delayed surgical intervention leads to reduced improvement in symptoms

10. Wormald PJ, van Renen G, Perks J, Jones JA, Langton-Hewer CD. The effect of the total intravenous anesthesia compared with inhalational anesthesia on the surgical field during endoscopic sinus surgery. Am J Rhinol. 2005;19:514-20.

11. Valentine R, Wormald P-J, Sindwani R. Advances in absorbable biomaterials and nasal packing. Otolaryngol Clin North Am. 2009;42:813-28 ix.

12. Valentine R, Wormald P-J. Are routine dissolvable nasal dressings necessary following endoscopic sinus surgery? Laryngoscope. 2010;120:1920-1.

13. Seredyka-Burduk M, Burduk PK, Wierzchowska M, Kaluzny B, Malukiewicz G. Ophthalmic complications of endoscopic sinus surgery. Braz J Otorhinolaryngol. 2017;83:318-23.

14. Yang Y-X, Lu Q-K, Liao J-C, Dang R-S. Morphological characteristics of the anterior ethmoidal artery in ethmoid roof and endoscopic localization. Skull Base. 2009;19:311-7.

15. Ferrari M, Pianta L, Borghesi A, Schreiber A, Ravanelli M, Mattavelli D, et al. The ethmoidal arteries: a cadaveric study based on cone beam computed tomography and endoscopic dissection. Surg Radiol Anat. 2017;39:991-8.

16. Kennedy D. Diseases of the sinuses: diagnosis and management. Hamilton: B.C. Decker; 2001.

17. Wu H, Shen T, Chen J, Yan J. Long-term therapeutic outcome of ophthalmic complications following endoscopic sinus surgery. Medicine (Baltimore). 2016;e4896:95.

18. Gellrich N-C, Schramm A, Rustemeyer J, Schon R, Theodor EU. Quantification of the neurodegenerative impact on the visual system following sudden retrobulbar expanding lesions - an experimental model. J Craniomaxillofac Surg. 2002;30:230-6.

19. Moeller CW, Welch KC. Prevention and management of complications in sphenoidotomy. Otolaryngol Clin North Am. 2010;43:83954.

20. Boling CC, Karnezis TT, Baker AB, Lawrence LA, Soler ZM, Vandergrift WA 3rd, et al. Multi-institutional study of risk factors for perioperative morbidity following transnasal endoscopic pituitary adenoma surgery. Int Forum Allergy Rhinol. 2016;6:101-7.

21. Gardner PA, Snyderman CH, Fernandez-Miranda JC, Jankowitz BT. Management of major vascular injury during endoscopic endonasal skull base surgery. Otolaryngol Clin North Am. 2016;49:819-28.

22. Chin OY, Ghosh R, Fang CH, Baredes S, Liu JK, Eloy JA. Internal carotid artery injury in endoscopic endonasal surgery: a systematic review. Laryngoscope. 2016;126:582-90. 
23. Padhye V, Valentine R, Paramasivan S, Jardeleza C, Bassiouni A, Vreugde S, et al. Early and late complications of endoscopic hemostatic techniques following different carotid artery injury characteristics. Int Forum Allergy Rhinol. 2014;4:651-7.

24. Modica PA, Tempelhoff R, Rich KM, Grubb RLJ. Computerized electroencephalographic monitoring and selective shunting: influence on intraoperative administration of phenylephrine and myocardial infarction after general anesthesia for carotid endarterectomy. Neurosurgery. 1992;30:842-6.

25. Chang JR, Grant MP, Merbs SL. Enucleation as endoscopic sinus surgery complication. JAMA Ophthalmol. 2015:850-2.

26. Ali MJ, Murphy J, Wormald PJ, Psaltis AJ. Bony nasolacrimal duct dehiscence in functional endoscopic sinus surgery: radiological study and discussion of surgical implications. J Laryngol Otol. 2015;129(Suppl):S35-40.

27. Ramakrishnan VR, Kingdom TT, Nayak JV, Hwang PH, Orlandi RR. Nationwide incidence of major complications in endoscopic sinus surgery. Int. Forum Allergy Rhinol. 2012;2:34-9.

28. Baban MIA, Hadi M, Gallo S, Zocchi J, Turri-Zanoni M, Castelnuovo P. Radiological and clinical interpretation of the patients with CSF leaks developed during or after endoscopic sinus surgery. Eur Arch Otorhinolaryngol. 2017;274:2827-35.

29. Ishii Y, Tahara S, Teramoto A, Morita A. Endoscopic endonasal skull base surgery: advantages, limitations, and our techniques to overcome cerebrospinal fluid leakage: technical note. Neurol Med Chir (Tokyo). 2014;54(Suppl 3):983-90.

30. Kljajic V, Vulekovic P, Vlaski L, Savovic S, Dragicevic D, Papic V. Endoscopic repair of cerebrospinal fluid rhinorrhea. Braz J Otorhinolaryngol. 2017;83:388-93.

31. Sharma SD, Kumar G, Bal J, Eweiss A. Endoscopic repair of cerebrospinal fluid rhinorrhoea. Eur Ann Otorhinolaryngol Head Neck Dis. 2016;133:187-90.

32. Hassab MH, Eweiss AZ, Ibrahim AA. Missed skull base injury during sinonasal surgery: a dangerous scenario still existing. Ear Nose Throat J. 2015;94:E37-42.

33. Vemuri NV, Karanam LSP, Manchikanti V, Dandamudi S, Puvvada SK, Vemuri VK. Imaging review of cerebrospinal fluid leaks. Indian J Radiol Imaging. 2017;27:441-6 Available from: https:// www.ncbi.nlm.nih.gov/pmc/articles/PMC5761172/.

34. Hara T, Akutsu H, Yamamoto T, Tanaka S, Takano S, Ishikawa E, et al. Cranial base repair using suturing technique combined with a mucosal flap for cerebrospinal fluid leakage during endoscopic endonasal surgery. World Neurosurg. 2015;84:1887-93.

35. Virk JS, Elmiyeh B, Saleh HA. Endoscopic management of cerebrospinal fluid rhinorrhea: the charing cross experience. J Neurol Surg B Skull Base. 2013;74:61-7.

36. Virk JS, Elmiyeh B, Stamatoglou C, Saleh HA. Optimising outcomes in the management of spontaneous cerebrospinal fluid rhinorrhoea. Rhinology. 2013;51:268-74.

37. Hsu AK, Singh A, Bury S, Schwartz TH, Anand VK, Kacker A. Endoscopic cerebrospinal fluid leak closure in an infected field. Am J Rhinol Allergy. 2015;29:305-8.

38. Daudia A, Biswas D, Jones NS. Risk of meningitis with cerebrospinal fluid rhinorrhea. Ann Otol Rhinol Laryngol. 2007;116:9025.

39. Pillai P, Sharma R, MacKenzie L, Reilly EF, Beery PR 2nd, Papadimos TJ, et al. Traumatic tension pneumocephalus - two cases and comprehensive review of literature. Int J Crit Illn Inj Sci. 2017;7:58-64 Available from: https://www.ncbi.nlm.nih.gov/pmc/ articles/PMC5364769/.

40. Celikoglu E, Hazneci J, Ramazanoglu AF. Tension pneumocephalus causing brain herniation after endoscopic sinus surgery. Asian J Neurosurg. 2016;11:309-10.

41. Guvenc G, Eren E, Arslanoglu S, Yuceer N. A rare complication of septoplasty: tension pneumocephalus without rhinorrhea. J Craniofac Surg. 2014;25:e360-1.
42. Aksoy F, Dogan R, Ozturan O, Tugrul S, Yildirim YS. Tension pneumocephalus: an extremely small defect leading to an extremely serious problem. Am J Otolaryngol. 2013;34:749-52.

43. Bly RA, Morton RP, Kim LJ, Moe KS. Tension pneumocephalus after endoscopic sinus surgery: a technical report of multiportal endoscopic skull base repair. Otolaryngol Head Neck Surg. 2014;151:1081-3.

44. Bewick J, Egro FM, Masterson L, Javer AR, Philpott CM. Anatomic findings in revision endoscopic sinus surgery: case series and review of contributory factors. Allergy Rhinol (Providence). 2016;7:e151-7.

45. Suzuki S, Yasunaga H, Matsui H, Fushimi K, Kondo K, Yamasoba T. Complication rates after functional endoscopic sinus surgery: analysis of 50,734 Japanese patients. Laryngoscope. 2015;125: 1785-91.

46. Philpott C, Hopkins C, Erskine S, Kumar N, Robertson A, Farboud A, et al. The burden of revision sinonasal surgery in the UK-data from the Chronic Rhinosinusitis Epidemiology Study (CRES): a cross-sectional study. BMJ Open. 2015;5:e006680.

47. Wu AW, Ting JY, Platt MP, Tierney HT, Metson R. Factors affecting time to revision sinus surgery for nasal polyps: a 25 -year experience. Laryngoscope. 2014;124:29-33.

48. Fokkens WJ, Lund VJ, Mullol J, Bachert C, Alobid I, Baroody F, et al. European position paper on rhinosinusitis and nasal polyps 2012. Rhinol Suppl. 2012;23:3 p preceding table of contents:1298.

49. Masterson L, Tanweer F, Bueser T, Leong P. Extensive endoscopic sinus surgery: does this reduce the revision rate for nasal polyposis? Eur Arch Otorhinolaryngol. 2010;267:1557-61.

50. Krings JG, Kallogjeri D, Wineland A, Nepple KG, Piccirillo JF, Getz AE. Complications of primary and revision functional endoscopic sinus surgery for chronic rhinosinusitis. Laryngoscope. 2014;124:838-45.

51. de Moreta GS, Cardoso-Lopez I, Poletti-Serafini D. Centripetal endoscopic sinus surgery in chronic rhinosinusitis: a 6-year experience. Am J Rhinol Allergy. 2014;28(4):349-52.

52. Amar YG, Frenkiel S, Sobol SE. Outcome analysis of endoscopic sinus surgery for chronic sinusitis in patients having Samter's triad. J Otolaryngol. 2000;29:7-12.

53. Morrissey DK, Bassiouni A, Psaltis AJ, Naidoo Y, Wormald P-J. Outcomes of modified endoscopic Lothrop in aspirin-exacerbated respiratory disease with nasal polyposis. Int Forum Allergy Rhinol. 2016;6:820-5

54. Anari S, Carrie S. Sinonasal inverted papilloma: narrative review. J Laryngol Otol. 2010;124:705-15.

55. Krouse JH. Development of a staging system for inverted papilloma. Laryngoscope. 2000;110:965-8.

56. Adriaensen GFJPM, Lim K-H, Georgalas C, Reinartz SM, Fokkens WJ. Challenges in the management of inverted papilloma: a review of 72 revision cases. Laryngoscope. 2016;126:322-8.

57. Kawada M, Yokoi H, Maruyama K, Matsumoto Y, Yamanaka H, Ikeda $\mathrm{T}$, et al. Rhinogenic intracranial complication with postoperative frontal sinus pyocele and inverted papilloma in the nasal cavity: a case report and literature review. SAGE Open Med Case Rep. 2016;4:2050313X16629828

58. Verillaud B, Le Clerc N, Blancal J-P, Guichard J-P, Kania R, Classe $\mathrm{M}$, et al. Mucocele formation after surgical treatment of inverted papilloma of the frontal sinus drainage pathway. Am J Rhinol Allergy. 2016;30:181-4.

59. Sama A. Indications for the use of the osteoplastic flap, with or without obliteration, in the management of frontal sinus disease in the endoscopic era. J. Ent Mastercl. 2012;5:138.

60. DeParis SW, Goldberg AN, Indaram M, Grumbine FL, Kersten RC, Vagefi MR. Paranasal sinus mucocele as a late complication of dacryocystorhinostomy. Ophthalmic Plast Reconstr Surg. 2017;33:S23-4. 
61. Jimenez-Chobillon M-A, Martinez-Castillo FA, Valdes-Hernandez E, Cristerna-Sanchez L. Refinement of the nasalisation technique for nasal polyposis. Eur Ann Otorhinolaryngol Head Neck Dis. 2016;133:237-41.

62. Kim S-J, Shin J-M, Lee EJ, Park I-H, Lee H-M, Kim K-S. Efficacy of hyaluronic acid and hydroxyethyl starch in preventing adhesion following endoscopic sinus surgery. Eur Arch Otorhinolaryngol. 2017;274:3643-9.

63. Kim JH, Lee J-H, Yoon J, Chang JH, Bae JH, Kim K-S. Antiadhesive effect of the mixed solution of sodium hyaluronate and sodium carboxymethylcellulose after endoscopic sinus surgery. Am J Rhinol. 2007;21:95-9.

64. Khanna A, Sama A. New instrumentations in the operating room for sinus surgery. Curr Opin Otolaryngol Head Neck Surg. 2018;26: $13-20$.
65. American Academy of Otolaryngology - Head and Neck Surgery. AAO HNS position statement: intra-operative use of computer aided surgery [Internet]. Available from: http://www.entnet.org/ content/intra-operative-use-computer-aided-surgery.

66. Dalgorf DM, Sacks R, Wormald P-J, Naidoo Y, Panizza B, Uren B, et al. Image-guided surgery influences perioperative morbidity from endoscopic sinus surgery: a systematic review and meta-analysis. Otolaryngol Head Neck Surg. 2013;149:17-29.

Publisher's Note Springer Nature remains neutral with regard to jurisdictional claims in published maps and institutional affiliations. 